\title{
Eastern Seaboard Electric Grid Fragility Maps Supporting Persistent Availability
}

\author{
Oak Ridge National Laboratory \\ Kimberly A. Walker
}

August 10, 2012

\begin{abstract}
Persistently available power transmission can be disrupted by weather causing power outages with economic and social consequences. This research investigated the effects on the national power grid from a specific weather event, Hurricane Irene, that caused approximately 5.7 million customer power outages along the Eastern Seaboard in August of 2011. The objective was to describe the geographic differences in the grid's vulnerability to these events. Individual factors, such as wind speed or precipitation, were correlated with the number of outages to determine the greatest mechanism of power failure in hopes of strengthening the future power grid. The resulting fragility maps not only depicted 18 counties that were less robust than the design-standard robustness model and three counties that were more robust, but also drew new damage contours with correlated wind speeds and county features.
\end{abstract}

\section{Introduction}

The $21^{\text {st }}$ century is burdened with several electricity challenges that include: economic growth, environmental regulation, climate driven extreme weather, advanced new technologies, transportation integration, higher electric system efficiency, and the creation of a smart grid. This research specifically investigated vulnerabilities in the current Eastern Grid that must be addressed to create a smart grid that is resilient and robust. By analyzing Hurricane Irene meteorological (METAR) data wind speed was correlated with fractions of household outages to identify areas of increased vulnerability. 
The United States' electric power is supplied and transmitted by the bulk transmission grid, which is segmented into three distinct, large grids called Interconnections: the Eastern Interconnection, the Western Electricity Coordinating Council, also known as the Western Interconnection, and the Electric Reliability Council of Texas (ERCOT) or simply Texas [1] (Fig. 1).

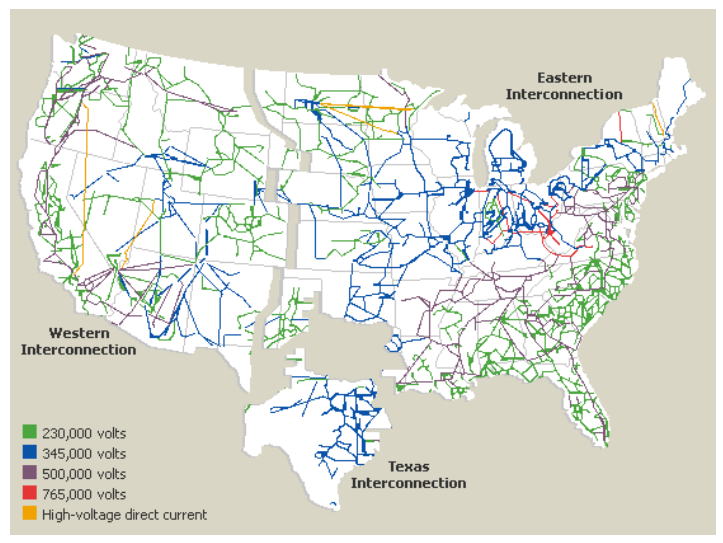

Figure 1: The interconnections of the United States and mapping of transmission lines with their corresponding voltage capacities.

Electricity is first carried from the generating station through bulk transmission lines, to the substations, and then distributed through lower voltage lines, or distribution lines, among the customers (Fig. 2).

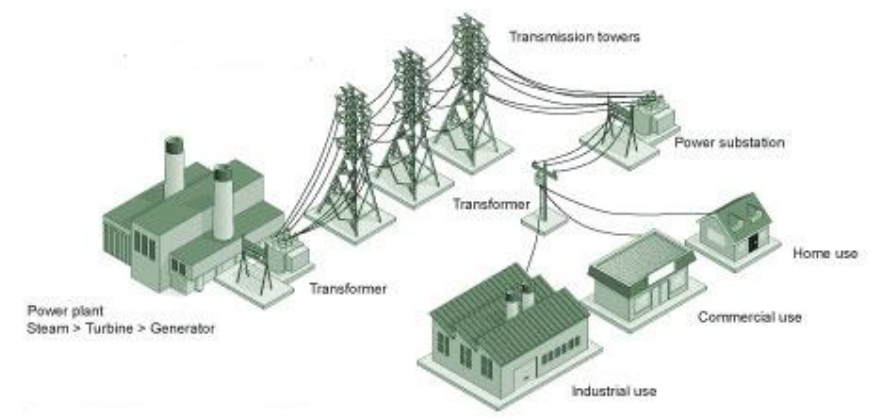

Figure 2: This shows a diagram of the electric power generation and distribution system.

Electricity is transmitted at high voltages of 65 kilovolts $(\mathrm{kV})$ or above and in a three phase alternating current (AC). However, some systems like railways use single phase AC [1]. An AC circulates clockwise around the circuit loop and then switches counter clockwise several times each second. The United States' AC alternates with a frequency of about 60 cycles per second or a power frequency of $60 \mathrm{Hertz}$ (Hz). However, the AC has a flaw. Two times every cycle (120 times per second) current stops. To 
prevent current loss, the nation implements the three phase $A C$ so that as one phase reaches a peak the other two have not yet peaked keeping current flowing (Fig. 3). Because the AC follows the Laws of Physics, power is equal to voltage multiplied by current (Eq. 1) and current is equal to voltage divided by the resistance of the wire (Eq. 2) [4].

Equation 1: $P=E^{*} \mid \quad$ For both equations, $P$ is the power in Watts, $E$ is the voltage in Volts, $I$ is the current in Amps, and $R$ is the Equation $2: \mathrm{I}=\mathrm{E} / \mathrm{R} \quad$ resistance in Ohms.

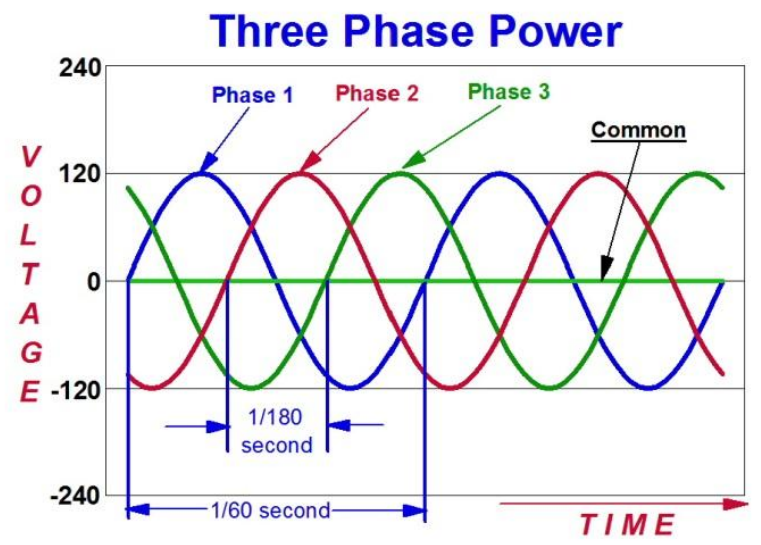

Figure 3: This demonstrates the three phase AC. Since each phase is out of phase with each other current can continue to flow unimpeded.

Because electricity is transmitted at high voltages to minimize the transmission losses the generators must be constantly monitored so that total output does not exceed the limitations of the transmission wires. The grid is mostly monitored automatically and sensors detect any errors in the system so that operators can disconnect the affected portion and reconnect it when it is operable again. This is known as automatic generation control (AGC). However, operators use systems known as Supervisory Control and Data Acquisition (SCADA) that allows them to analyze the power output in each electric network to provide judgment to determine the best course of corrective action [7].

There are two main types of infrastructure that transmit electricity in the grid: overhead and underground. Overhead wires are suspended by towers and utility poles made with a combination of 
wood, steel, aluminum, and reinforced plastics. In some low voltage areas, copper wires are used to transmit electricity to customers. Because these wires are operated around $750 \mathrm{kV}$, a continuing challenge is to maintain enough clearance between conductors and the ground to prevent dangerous faults [8].

Overhead lines are more resilient than robust systems because they are vulnerable to failure from high winds but recover quickly, and are easy to build, maintain, and repair. The construction of these lines is relatively cheap at about ten dollars per foot [9].

For example, if a customer loses power due to a storm the repair crew climbs up to repair any damages. However, these lines are vulnerable to power disruption caused by weather. Falling tree limb or strong winds can easily sever its connection. However, since repair crews can easily access them, these lines can quickly recover from outage, making them resilient.

Underground lines are robust systems because they are able to remain intact during many types of severe weather phenomena that do not penetrate the ground as floods or as earthquakes do. They serve as alternatives to the overhead lines, especially when feasible above-ground routes are unavailable. Underground lines do have a few above ground terminals, but are basically protected. Because they are not as easily perturbed by weather events such wind, lightning, or ice they are better protected against power failure, and are considered robust. It takes one to ten meters to install underground wires, but overhead wires require about 20 to 200 meters. Because these lines are buried, the emission of electromagnetic fields into the environment is reduced, no hazards to low flying planes or wildlife are posed, and are less threatened to be stolen or to have illegal connections [9].

Despite all these advantages, underground lines have two large disadvantages: price and repair time, making them much less resilient than overhead lines. According to a 2007 study by Entergy Texas, it would cost $\$ 5$ million to build underground wires versus $\$ 50,000$ for overhead wires. According to another study in 2006 by the Edison Electric Institute, burying overhead lines would approximately cost 
$\$ 1$ million per mile, which is equal to about 10 times the amount that it would cost to install overhead lines. When these lines sustain damage it takes about $60 \%$ longer to repair them than it does for overhead systems, because specially trained and certified earth movers have to be involved. Because of the difficulty of accessing these lines, constant maintenance is another issue. According to Maryland utilities, their underground cables become unreliable after about 15 to 20 years and reach their end life time at 25 to 35 years [2].

In this project, Hurricane Irene data was analyzed in hopes of examining the two factors of resiliency and robustness to strengthen the national grid. Hurricane Irene was an opportune storm because it simultaneously exposed a large number of counties to wind and rain with diverse grid system characteristics of position, elevation, infrastructure, and nature.

Oak Ridge National Laboratory (ORNL) provided a centralized data set that accessed the utility companies' data through the National Outage Map (NOM). Fragility maps that displayed the percentage of customer outages, wind speed, and new damage contours were created to better model a storm's effect on those counties and to inform the utility companies of what to expect during future storms. In the next section, detailed steps on the creation of the fragility maps are discussed.

\section{Experimental Methods}

The first task was to geo-locate the counties in the 15 states affected by Hurricane Irene and record the geographical position of their county seats that represented the center of each county. Geo-location was completed in two steps. First, the counties were associated with their county centers. Then the result was imported into the geographical analysis software package ArcGIS 10. Within ArcGIS the counties were matched with their longitude and latitude points and their Federal Information Processing Standard (FIPS) code [3].

The meteorological (METAR) stations were located in the same affected states within a National Oceanic and Atmospheric Administration (NOAA) website that listed each station with its longitude and 
latitude points [5]. However, the website displayed the geographical positions in degrees, minutes, and seconds, which were then converted to decimal degrees with an online conversion table.

The METAR stations were separated and matched with their respective county. Therefore, the last two steps required modeling because each county did not have its own station. This modeling was performed in ArcGIS by using a proximity analysis, built-in tool called "near". By importing the two sets of data of county seats and METAR locations, the "near" tool matched them by shortest distance between the graphical locations [3].

Simultaneously, METAR data was being gathered from the National Outage Map (NOM). This data was formatted in several different ways including: keyhole markup language (KML), shape files, and Excel spreadsheets. All the data was converted to Excel format to be manipulated for analysis. Data sets that divided states into counties with their matched METAR stations sustained and gusted winds, precipitation, and number of customer outages that were all dependent on time were created in Microsoft Excel. However, the NOM data showed significant outages of a small sampling of the counties most severely impacted by the storm. Therefore, the Excel data sheets were reduced to only cover those states and counties that were supported by the NOM.

An urgent request came from the Federal Emergency Management Agency (FEMA). FEMA was specifically interested in the Washington D.C., Virginia, and Maryland area because all three of these areas lost power at the same time and belonged to similar utility companies, but the restoration time was fast for Virginia and much slower for D.C. and Maryland. For their request, data was taken from the NOM Movie of Hurricane Irene by inspection. The movie covered Hurricane Irene for a ten day period from August 19, 2011 at 8:00pm until August 29, 2011 at 7:59pm. In this movie, states displayed colors that represented the percent of customers out of power. Wind barbs were also represented as vectors 
that depicted the angle of orientation and the magnitude of the wind strength (Fig. 4).

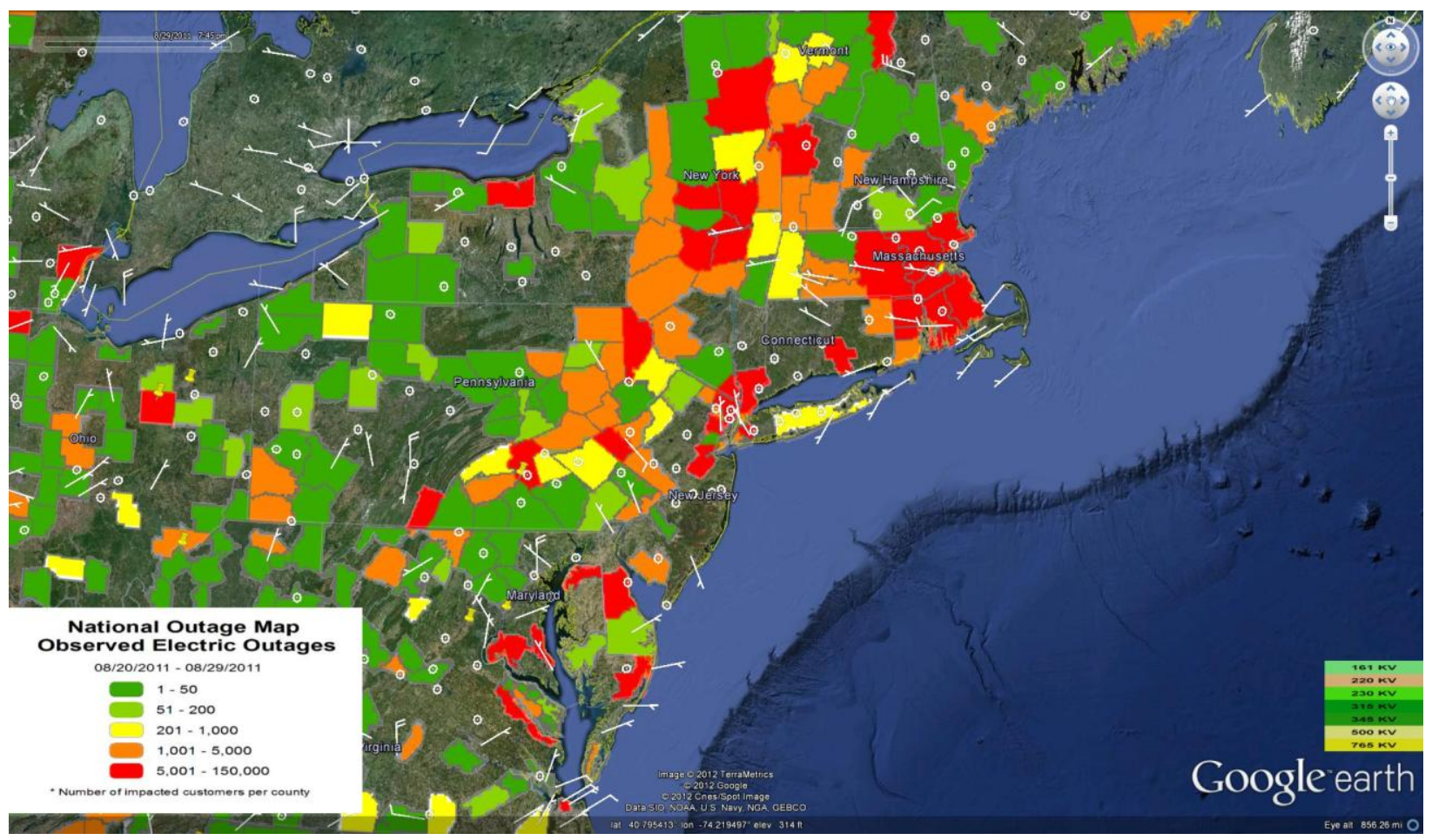

Figure 4: This displays an example of the National Outage Map Movie with Wind Barbs. The counties are highlighted with the color of percent of outages. The legend for these colors can be seen on the bottom left of this image in the white box. Wind barbs are also depicted at the angle of orientation and how strong they are depending on how many short flags are drawn. The circles are wind barbs that mean calm winds.

As the counties changed color, those colors and wind speeds were recorded. When the movie finished, the color transitions were highlighted at the significant changes such as green to yellow, green to orange, and green to red. The wind speed at each transition was recorded and provided an estimate of the important county vulnerability points. Next, this data was created into damage threshold fragility maps that displayed wind speed on the $y$ axis and counties on the $x$ axis. By applying a line of best fit, this created new damage threshold distinctions for these counties. 
After that goal was competed, the number of customer outages was correlated with wind speed. This data created another set of fragility maps that represented the relationship between outages and wind magnitude. With both sets of fragility maps, the data was analyzed to determine what wind speed will create a probability of power loss for a specific county and state. This data analysis is discussed in the Results section.

\section{Results}

From the initial set of 531 counties, only about a 100 of those had "good" data, meaning that the data from the national outage map actually reported customer outages. From FEMA's request about six fragility maps were plotted that depicted sustained and gusted winds versus the counties that displayed the sudden damage color peak (Fig. 5).

\begin{tabular}{|c|c|c|}
\hline County, State & Sustained Wind (Knots) & Figure 5: This table depicts counties \\
\hline Calvert, Maryland & 18 & and states with their corresponding \\
\hline Bergen, New Jersey & 17 & sustained wind speed when the \\
\hline Bristol, Rhode Island & 32 & (1-50 customer outages) to red \\
\hline Kent, Rhode Island & 32 & (5,001-150,000 customer outages). \\
\hline
\end{tabular}

These initial maps provided a basis to determine which counties were the most susceptible to damage from sustained and gusted winds. However, when more of the METAR data was sorted, more exact fragility maps were created. These maps consisted of three scales: the individual county level, the state level, and the aggregated states level to represent the Eastern Seaboard. The county level was important because repair-response time crews are supplied on a county level to meet the needs of the customers. The state levels are important because each state individually issues standards for the construction of transmission lines. This specification is an "as designed" basis. While a general guideline currently used in models, forecasts are improved if "as built" damage thresholds are used (Fig. 6). 


\begin{tabular}{|l|l|}
\hline State & $\begin{array}{l}\text { Wind Speed } \\
\text { (Knots) }\end{array}$ \\
\hline New Hampshire & 9 \\
\hline New York & 38 \\
\hline North Carolina & 80 \\
\hline Pennsylvania & 5 \\
\hline Rhode Island & 7 \\
\hline Virginia & 8 \\
\hline
\end{tabular}

Figure 6: This chart depicts the states that had $50 \%$ customer outages and their corresponding wind speeds.

The fragility map with the aggregated states displayed the most significance because the peak damage thresholds can be easily seen, which directly shows the areas of the Eastern Seaboard that are most likely to experience high and low customer outages. Along with these peaks, new, "as-built" generic damage thresholds were drawn because now exact wind speeds are known that produce those thresholds (Fig.7).
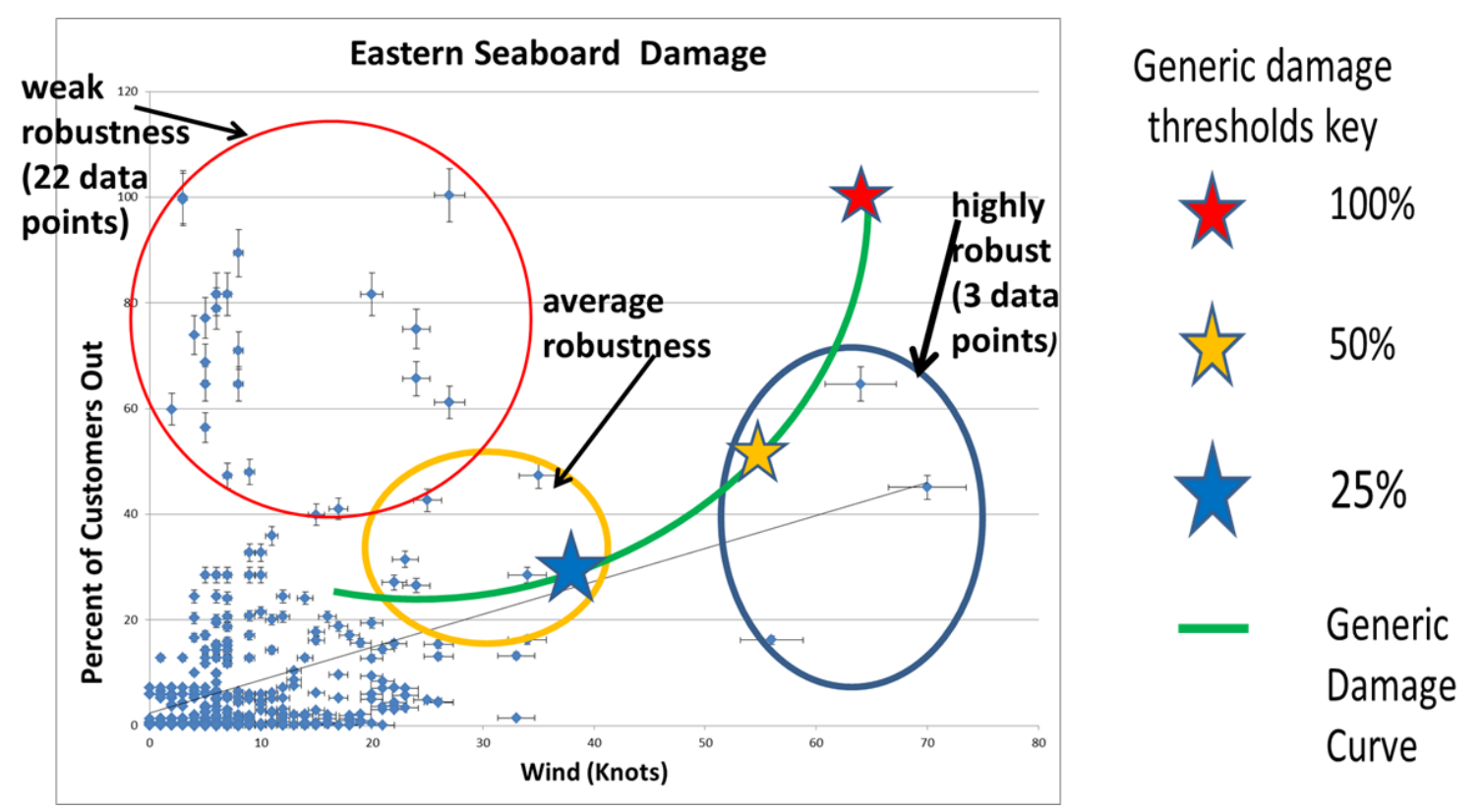

Figure 7: This is the aggregated states fragility map that depicts an allcounty measure of robustness.

In Figure 7, the points inside the red circle are the counties that are weakly robust because they experience high customer outages at low wind speeds. This area contained about 22 data points 
representing only 18 distinct counties. Some of the counties were doubled as they experienced different wind speeds and customer outages. The data points in the yellow circle are the average robust counties. These counties fit the generic model because they lie on the green, generic, damage curve. Lastly, the three points circled in blue are the highly robust counties because they experienced low customer outages at very high wind speeds. The stars on Figure 7 illustrate the existing $25 \%$ "as-designed" thresholds, 50\% probability of "as-designed" damage, and 100\% damage "as designed" threshold. In next section, further deductions of the significance of these charts are discussed.

\section{Conclusion}

From analysis of the aggregated states fragility map, the weakly robust counties (Fig.8) and the highly robust counties (Fig. 9) can be separated. There are some hypothesized reasons as to why these counties were either weakly or highly robust.

The weakly robust counties may have had overhead wires that were not well maintained or placed. Tree limbs may have fallen on the lines at a low wind speed causing the power outage or the quality of the wire may have been old and wore out. Another reason is that the substations may have been in direct path of the storm and not well maintained causing them to be damaged. These counties were also close to water with very low and flat elevation. Therefore, their outages may not have been due to their experienced winds, but instead to the extensive flash flooding documented to have occurred in the area. The number of customers that live in these counties that depend on a common utility company could have also played an important role. The highly robust counties must have had either underground wires or their above ground wires were well placed and maintained. These counties' substations may have not been in the direct path of the storm. These counties were mostly land locked and had high, mountainous elevation that could have protected their substations from harsh winds and flooding. 
Figure 8: These are the weakly robust counties.

\begin{tabular}{|l|l|l|l|}
\multicolumn{1}{c|}{ State } & \multicolumn{1}{|c|}{ County } & $\begin{array}{c}\text { Wind } \\
\text { (Knots) }\end{array}$ & $\begin{array}{c}\text { Customer } \\
\text { Outages }\end{array}$ \\
\hline Delaware & Kent & 4 & $73.94 \%$ \\
\hline Massachusetts & Norfolk & 9 & $47.98 \%$ \\
\hline Massachusetts & Plymouth & 8 & $70.97 \%$ \\
\hline New York & Greene & 20 & $81.64 \%$ \\
\hline New York & Otsego & 15 & $39.92 \%$ \\
\hline North Carolina & Schoharie & 17 & $41.00 \%$ \\
\hline North Carolina & Carteret & 27 & 61.15 \\
\hline North Carolina & Craven & 5 & $77.13 \%$ \\
\hline North Carolina & Edgecombe & 27 & $100.4 \%$ \\
\hline North Carolina & Jones & 5 & $56.39 \%$ \\
\hline North Carolina & Lenoir & 5 & $68.73 \%$ \\
\hline North Carolina & Pamlico & 3 & $99.98 \%$ \\
\hline Pennsylvania & Greene & 6 & $81.64 \%$ \\
\hline Pennsylvania & Sullivan & 5 & $64.66 \%$ \\
\hline Rhode Island & Newport & 6 & $78.94 \%$ \\
\hline Virginia & Bristol & 2 & $59.84 \%$ \\
\hline Virginia & Greene & 7 & $81.64 \%$ \\
\hline Virginia & Halifax & 7 & $47.31 \%$ \\
\hline & & &
\end{tabular}

Figure 9: These are the highly robust counties.

\begin{tabular}{|l|l|l|l|}
\hline State & County & $\begin{array}{l}\text { Wind } \\
\text { (Knots) }\end{array}$ & $\begin{array}{l}\text { Customer } \\
\text { Outages }\end{array}$ \\
\hline New York & Sullivan & 64 & $64.66 \%$ \\
\hline $\begin{array}{l}\text { North } \\
\text { Carolina }\end{array}$ & Nash & 70 & $45.08 \%$ \\
\hline $\begin{array}{l}\text { North } \\
\text { Carolina }\end{array}$ & Wilson & 56 & $16.19 \%$ \\
\hline
\end{tabular}

Some recommendations prevent themselves to decrease the data uncertainties. First, the METAR only reports on an hourly basis while outage information was reported at 15 minute intervals. The time mismatch may have added to the uncertainty of the wind speed that caused the observed outages. The data should be taken in the same time increments to get a clear, direct correlation.

Overall, since it is now known which counties are weakly robust in the Eastern Seaboard area, these are the counties that need to strengthen their infrastructure to decrease the number of power outages caused by hurricane-like weather events. Once these counties are better fortified, perhaps other similar counties throughout the nation can use these as an example to improve their infrastructure to become more robust and even more resilient, which would continue to strengthen the national power grid.

\section{Discussion}

Empirical data is available to create better "as-built" generic damage contours, a better county-bycounty hurricane model to predict the impact of future storms, and better customer and utility forecasts to plan and respond to future storms. An indirect positive consequence of this project is that customers and utilities now have the chance to improve their communication methods to improve their repair and response time since this data is easily accessible. With all these factors combined emergency responders 
can now better make their customers be aware of potential outages and provide their customers with better time estimates on when power will be restored.

Some future questions include looking at the edges of the storm where the uncertainty of the events is greater. For example, smaller storms can form around the outer edges of the main storm event. This can cause different effects than straight line wind and is more appropriate for tornado events. Further work is needed to study the effects of lighting and debris. An open question is whether strong sustained winds cause more damage than strong gusts, which in turn asks if sustained and gusted winds should be treated as independent or dependent variables. Overall, these study areas address the vast question, "With what is now known, how can the national power grid become even more robust and resilient?"

\section{Resources}

[1] "Electric Power Transmission." Wikimedia Foundation, n.d. Web. 19 June 2012." <http://en.wikipedia.org/wiki/Electric_power_transmission>.

[2] Entergy. "Should Power Lines Be Underground?" (n.d.): n. pag. Web. 12 July 2012.

[3] ESRI 2011. ArcGIS Desktop: Release 10. Redlands, CA: Environmental Systems Research Institute.

[4] Hayes, Brian. Infrastructure: The Book of Everything for the Industrial Landscape. New York [u.a.: Norton, 2005. Print.

[5] "Meteorological Products Processed At The NWSTG." Meteorological Products Processed At The NWSTG. National Oceanic and Atmospheric Administration, US Department of Commerce, 11 Dec. 2003. Web. 11 July 2012. <http://www.nws.noaa.gov/tg/siteloc.shtml>.

[6] Oak Ridge National Laboratory. Visualizing Energy Resources Dynamically on Earth (VERDE). Computer software. Oak Ridge National Laboratory, 22 Jan. 2010. Web. 4 June 2012.

[7] Overbye, Thomas J. "Power Systems Operations and Visualization." Power Systems Engineering Research Center (2003): n. pag. Print.

[8] "Overhead Power Line." Wikipedia. Wikimedia Foundation, 07 May 2012. Web. 12 July 2012. <http://en.wikipedia.org/wiki/Overhead_power_line>.

[9] "Undergrounding." Wikipedia. Wikimedia Foundation, 06 Feb. 2012. Web. 12 July 2012. <http://en.wikipedia.org/wiki/Undergrounding>. 